\title{
Worklife and Wellness in Academic General Internal Medicine: Results from a National Survey
}

\author{
Mark Linzer, MD ${ }^{1,2}$, Sara Poplau, BA ${ }^{7,3}$, Stewart Babbott, MD , Tracie Collins, MD, MPH', \\ Laura Guzman-Corrales, $\mathrm{MPH}^{3}$, Jeremiah Menk, MS $S^{6}$, Mary Lou Murphy, MS, RN ${ }^{7}$, and Kay Ovington, \\ $B A^{8}$
}

'Division of General Internal Medicine, Hennepin County Medical Center, Minneapolis, MN, USA; ${ }^{2}$ Department of Medicine, University of Minnesota, Minneapolis, MN, USA; ${ }^{3}$ Minneapolis Medical Research Foundation, Minneapolis, MN, USA; ${ }^{4}$ Department of Medicine, University of Kansas, Kansas City, KS, USA; 5 Department of Preventive Medicine and Public Health, University of Kansas School of Medicine, Wichita, KS, USA; ${ }^{6}$ Biostatistical Design and Analysis Center, Clinical and Translational Sciences Institute, University of Minnesota, Minneapolis, MN, USA; ${ }^{7}$ Center for Physician Wellness and Professional Fulfillment, Stanford Medicine, Palo Alto, CA, USA; ${ }^{8}$ Society of General Internal Medicine and Association of Chiefs and Leaders in General Internal Medicine, Alexandria, VA, USA.

BACKGROUND: General internal medicine (GIM) careers are increasingly viewed as challenging and unsustainable. OBJECTIVE: We aimed to assess academic GIM worklife and determine remediable predictors of stress and burnout. DESIGN: We conducted an email survey.

PARTICIPANTS: Physicians, nurse practitioners, and physician assistants in 15 GIM divisions participated.

MAIN MEASURES: A ten-item survey queried stress, burnout, and work conditions such as electronic medical record (EMR) challenges. An open-ended question assessed stressors and solutions. Results were categorized into burnout, high stress, high control, chaos, good teamwork, high values alignment, documentation time pressure, and excessive home EMR use. Frequencies were determined for national data, Veterans Affairs (VA) versus civilian populations, and hospitalist versus ambulatory roles. A General Linear Mixed Model (GLMM) evaluated associations with burnout. A formal content analysis was performed for open-ended question responses.

KEY RESULTS: Of 1235 clinicians sampled, 579 responded (47\%). High stress was present in $67 \%$, with $38 \%$ burned out (burnout range $10-56 \%$ by division). Half of respondents had low work control, $60 \%$ reported high documentation time pressure, half described too much home EMR time, and most reported very busy or chaotic workplaces. Two-thirds felt aligned with departmental leaders' values, and three-quarters were satisfied with teamwork. Burnout was associated with high stress, low work control, and low values alignment with leaders (all $p<0.001$ ). The 45 VA faculty had less burnout than civilian counterparts ( $17 \%$ vs. $40 \%, p<0.05$ ). Hospitalists described better teamwork than ambulatory clinicians and fewer hospitalists noted documentation time pressure (both $p<0.001$ ). Key themes from the qualitative analysis were short visits, insufficient support staff, a Relative Value Unit mentality, documentation time pressure, and undervaluing education.

Electronic supplementary material The online version of this article (doi:10.1007/s11606-016-3720-4) contains supplementary material, which is available to authorized users.

Received November 17, 2015

Revised February 26, 2016

Accepted April 19, 2016

Published online May 2, 2016
CONCLUSIONS: While GIM divisions overall demonstrate high stress and burnout, division rates vary widely. Sustainability efforts within GIM could focus on visit length, staff support, schedule control, clinic chaos, and EMR stress.

KEY WORDS: general internal medicine; stress; burnout; clinician burnout; physician satisfaction.

J Gen Intern Med 31(9):1004-10

DOI: $10.1007 / \mathrm{s} 11606-016-3720-4$

(c) Society of General Internal Medicine 2016

\section{INTRODUCTION}

Recently, authors have noted the challenges of worklife in primary care overall and in general internal medicine (GIM) in particular. ${ }^{1,2}$ These challenges lead to exhausting workdays, electronic medical record (EMR)-related distress, and diminishing attractiveness of primary care as a career for future doctors. ${ }^{3}$ A 2002 comparison of GIM worklife with family medicine (FM) and subspecialty internal medicine (SSIM) showed lower job satisfaction in GIM, with general internists spending more hospital time than FM doctors and more clinic time than SSIM physicians. ${ }^{2}$

Predictors of overall satisfaction in GIM include satisfaction with personal time, staff relationships, and sufficient resources; general internists are less likely than FM physicians to recommend their specialty to medical students. ${ }^{2}$ Predictors of career satisfaction include work-home balance and schedule control. ${ }^{4}$ Prior studies have demonstrated the relationship between increased hospital time (in predominantly ambulatorybased internists) and GIM stress and burnout, ${ }^{2}$ and a 2012 study found rising burnout among all disciplines, including GIM. ${ }^{5}$

However, GIM career satisfaction and worklife remain underexplored, particularly since the rise of hospital-based medicine as an independent career, separate from ambulatory-based GIM careers.

This study had three objectives: to catalogue worklife challenges among academic GIM divisions; to provide data 
cataloguing stress, burnout, and their predictors among general internists nationally; and to advise clinical and administrative leaders on targeted interventions to improve worklife, wellness, and career attractiveness within GIM. We undertook the study under the auspices of the Association of Chiefs and Leaders in General Internal Medicine (ACLGIM).

\section{METHODS}

In fall 2014, we advertised among 100 GIM division chiefs at national meetings and on SGIM Connect [a web-based virtual community for ACLGIM and SGIM (Society of General Internal Medicine) members] for participation in a project using the ten-item Mini $\mathrm{Z}$ survey to assess stress, burnout, and remediable predictors among division members. Fifteen divisions paid $\$ 1500$ each to enroll; only one division stated inability to afford the enrollment fee. Divisions were recruited from the Northeast, Mid-Atlantic, South, Midwest, and Western regions. The Human Subjects Research Committee at Hennepin County Medical Center categorized the project as a Quality Assurance program not requiring formal Institutional Review Board approval.

Subjects. Eligible participants included physicians and advanced practice providers (APPs, including nurse practitioners and physician assistants) at participating medical centers. We did not require a given clinical full-time equivalent (FTE) to participate. Clinicians per site ranged from approximately 20 to over 200. Many divisions included both hospital- and ambulatory-based clinicians. Several included Veterans Affairs (VA) and civilian clinicians. While researchoriented clinicians were eligible, there was no focus on research faculty's work lives in this project phase.

Study Design. The project was based upon the conceptual model from the MEMO (Minimizing Error Maximizing Outcome) study linking work conditions to clinician reactions (satisfaction, stress, and burnout) and patient outcomes (quality and errors). ${ }^{1}$ The Mini Z survey includes ten items adapted from the MEMO clinician survey. ${ }^{1} \mathrm{We}$ administered the Mini Z electronically via Survey Monkey to all clinicians at the 15 participating divisions in spring 2015. Division leaders provided email addresses. We sent three reminder emails before closing the project after 34 days. At the approximate midpoint of the survey time period, each division chief or appointed divisional wellness champion received the response rate for his or her division and strategies for improving that rate.

Measures. The Mini $\mathrm{Z}$ assessed satisfaction, stress, and burnout using single-item measures. It also assessed work control, clinic environment chaos (pace), teamwork, values alignment with departmental leaders, documentation time pressure, home EMR use, and EMR proficiency. Finally, an open-ended question asked, "Please tell us about your stressors and potential solutions." The Mini Z has been evaluated for reliability and validity through annual administration to all departments at Hennepin County Medical Center in Minneapolis, MN. ${ }^{6}$ Reliability is reasonable, with Cronbach's alpha of 0.8 for the entire measure and $0.72-0.74$ for two subscales including EMR/stress and teamwork/values. Internal validity was determined by a correlational analysis, with correlations between most predictor variables and burnout at the $p<0.001$ level. The single-item burnout measure has demonstrated very good correlations with the emotional exhaustion scale of the Maslach Burnout Inventory. ${ }^{7}$ Mini $\mathrm{Z}$ results for the ACLGIM survey were portrayed as "percent of faculty burned out," or "percent highly stressed," by coalescing the high or low scores on each scale for all clinicians within the division (see Online Appendix for scale and scoring). A demographic section allowed respondents to self-report ambulatory versus hospital-based care, years in practice, gender, and race/ ethnicity.

Quantitative Analysis and Data Dissemination. Tabular-form data noted percent of clinicians (physicians and APPs) stressed or burned out and percent experiencing chaos, low work control, high EMR stress, low values alignment, and good teamwork compared with national summary scores. Scores were compared for hospitalists versus ambulatory-based clinicians and for VA versus civilian clinicians. There were too few APPs to make meaningful comparisons with physicians. Females and males were also compared. Confidence intervals and unadjusted $p$ values were computed using Wilson's score statistic. $^{8}$ Statistical significance was assessed after adjusting for multiple comparisons using the method of $\mathrm{Holm}^{9}$ for ten comparisons for each of the between group analyses to maintain a family-wise error rate of 0.05 . National-level predictors of burnout were evaluated using a General Linear Mixed Model (GLMM) with a logit link and a random effect for division; variables included stress, chaos, control, values alignment, documentation time, home EMR time, and teamwork. Confidence intervals (95\%) were constructed using a likelihood profile and $p$ values were estimated using a zstatistic.

GIM chiefs and leaders received tabular-form data comparing their clinicians' data with national scores. Chiefs received a "Chief's packet" with the data, an interpretation of the findings, suggestions for targeted interventions, a reference list of additional scholarly work, the Mini Z with a "deep dive" (longer) instrument, and suggestions for leveraging data in conversations with the Chair to better understand GIM worklife and resources needed to address worklife challenges.

Qualitative Analysis. Over half of respondents submitted open-ended comments about stressors and potential solutions. Comments were transformed into an Excel spreadsheet and underwent formal content analysis by four reviewers who separately reviewed the transcripts, identified themes, and 
grouped themes into categories. Once saturation of themes occurred, two conference calls were held to discuss the themes and endorse key themes and categories. Qualitative results were triangulated with quantitative data to assess the final list and convert the data to tabular form.

\section{RESULTS}

Quantitative Findings. Of 1235 clinicians, 579 (47\%) responded. Table 1 shows respondent demographics. About $60 \%$ were female; about $20 \%$ did not identify as White. Most were physicians, were ambulatory based, and practiced in civilian facilities. Table 2 shows the national data. Most GIM clinicians were highly stressed $(67 \%)$ and over one-third were burned out (38\% average, range by division $10 \%$ to $56 \%$ ). Work control was marginal or poor in almost half of clinicians (49\%). Most workplaces (58\%) were very busy or chaotic. EMR-related stress was high, with $62 \%$ of clinicians reporting high documentation time pressure and over half $(57 \%)$ spending moderate to excessive time on the EMR at home. Favorable findings included $65 \%$ of faculty noting values alignment with leaders and $74 \%$ noting satisfactory to optimal team efficiency.

Table 1. Respondent Demographics in the ACLGIM Worklife and Wellness Project

\begin{tabular}{ll}
\hline \hline Overall & \\
\hline Provider Type & \\
MD/DO & $554(95.7 \%)$ \\
Nurse Practitioner & $12(2.1 \%)$ \\
Physician Assistant & $9(1.6 \%)$ \\
Other & $4(0.7 \%)$ \\
VA & \\
VA & $46(7.9 \%)$ \\
Non-VA & $533(92.1 \%)$ \\
Inpatient vs. outpatient & \\
Inpatient & $180(31.1 \%)$ \\
Ambulatory & $399(68.9 \%)$ \\
Experience & \\
0-1 year & $59(10.2 \%)$ \\
2-5 years & $168(29.0 \%)$ \\
6-10 years & $128(22.1 \%)$ \\
11-15 years & $83(14.3 \%)$ \\
16-20 years & $60(10.4 \%)$ \\
21+ years & $81(14.0 \%)$ \\
Gender & \\
Female & $352(60.8 \%)$ \\
Male & $210(36.3 \%)$ \\
No Response & $17(2.9 \%)$ \\
Race & \\
African American/African Born & $18(3.1 \%)$ \\
Asian & $74(12.8 \%)$ \\
White & $437(75.5 \%)$ \\
Multiracial/Other & $7(1.2 \%)$ \\
I prefer not to answer & $30(5.2 \%)$ \\
Missing & $13(2.2 \%)$ \\
Ethnicity & $18(3.1 \%)$ \\
Latino/Hispanic & $333(57.5 \%)$ \\
Not Latino/Hispanic & $20(3.5 \%)$ \\
I prefer not to answer & $208(35.9 \%)$ \\
No Response & \\
\hline
\end{tabular}

Table 2. National Data for 579 Clinicians in the ACLGIM Worklife and Wellness Project

\begin{tabular}{lc}
\hline \hline Response $\boldsymbol{N}$ / Total $\boldsymbol{N}$ (Response rate, \%) & $\begin{array}{l}\text { Total population } \\
(\mathbf{N = 5 7 9 / 1 2 3 5} \\
\mathbf{( 4 6 . 9 \% )}\end{array}$ \\
\hline MD & $554(95.7 \%)$ \\
APP & $\begin{array}{c}4(3.6 \%) \\
(0.7 \%)\end{array}$ \\
$\begin{array}{l}\text { Other } \\
\text { Overall satisfied with job (Agree, Strongly }\end{array}$ & $437(75.5 \%)$ \\
agree) & $388(67.0 \%)$ \\
$\begin{array}{l}\text { Great deal of stress because of my job (Agree, } \\
\text { Strongly agree) }\end{array}$ & $221(38.2 \%)$ \\
$\begin{array}{l}\text { Symptoms of burnout (Definitely, Won't go } \\
\text { away, Completely) }\end{array}$ & $281(48.5 \%)$ \\
$\begin{array}{l}\text { Control over workload (Poor, Marginal) } \\
\text { Time for documentation (Poor, Marginal) }\end{array}$ & $361(62.3 \%)$ \\
$\begin{array}{l}\text { Work atmosphere description (Very busy, } \\
\text { Hectic-chaotic) }\end{array}$ & $336(58.0 \%)$ \\
$\begin{array}{l}\text { Professional values aligned well with } \\
\text { department leaders (Agree, Strongly agree) }\end{array}$ & $378(65.3 \%)$ \\
$\begin{array}{l}\text { Degree patient care team works efficiently } \\
\text { together (Satisfactory, Good, Optimal) }\end{array}$ & $428(73.9 \%)$ \\
$\begin{array}{l}\text { Amount of time spent on EMR at home } \\
\text { (Moderate, High, Excessive) }\end{array}$ & $330(57.0 \%)$ \\
$\begin{array}{l}\text { Proficiency with EMR use (Satisfactory, Good, } \\
\text { Optimal) }\end{array}$ & $516(89.1 \%)$ \\
\hline
\end{tabular}

Hospital-based clinicians $(n=183)$ reported better worklives than ambulatory-based clinicians $(n=396)$, with less documentation time pressure (48\% time-pressured vs. $69 \%$ of ambulatory clinicians), fewer hospitalists with excessive EMR home time ( $46 \%$ vs. $62 \%$ ), and more hospitalist faculty noting high teamwork ( $87 \%$ vs. $68 \%$, all $p$ values $<0.001$ ) (Table 3). While hospital-based clinicians tended to note lower stress and burnout, these differences were not statistically significant after adjusting for multiple comparisons. Only 45 VA clinicians responded, a relatively small proportion $(<$ $10 \%$ ) of the total sample. However, their data suggested potentially important differences from civilian clinicians, with fewer burned-out VA clinicians (17\% vs. $40 \%$ ), fewer clinicians with documentation time pressure ( $35 \%$ vs. $65 \%$ ), and fewer noting high EMR home use (30 \% vs. $59 \%$, all $p$ values $<0.05)$. APP respondents $(n=21)$ were too few to allow meaningful comparisons with physician colleagues. While women $(n=352)$ reported higher stress and burnout than men $(n=210$ males, $71 \%$ of women respondents highly stressed vs. $62 \%$ of males, $40 \%$ burned out vs. $36 \%$ of males), the differences were not statistically significant after adjusting for multiple comparisons.

One unit with a high response rate $(84 \%)$ had a very low burnout rate $(10 \%)$. This "best practice" site, combining hospitalist, outpatient, and VA clinicians, described high job satisfaction in $95 \%$ of respondents, low stress, low burnout, high control over workload, low EMR stress (with sufficient documentation time and little EMR home use), low chaos, and high values alignment with leaders (90\%).

A GLMM evaluated associations with burnout in the national sample and also sought protective factors associated with low burnout. High stress [OR $(95 \% \mathrm{CI}): 13.7$ (7.0, $29.4)]$ and poor work control [OR $(95 \% \mathrm{CI})$ : $4.3,(2.7,6.9)]$ were associated with burnout (both $p$ values $<0.001$ ). Burnout 
Table 3. Hospital-Based vs. Ambulatory-Based Clinicians in the ACLGIM Worklife and Wellness Project

\begin{tabular}{|c|c|c|c|c|}
\hline Item & $\begin{array}{l}\text { Hospitalist \% (95 \% CIs) } \\
(n=183)\end{array}$ & $\begin{array}{l}\text { Outpatient \% (95\% CIs) } \\
(n=396)\end{array}$ & $p$ value & $\begin{array}{l}\text { Adjusted } p \\
\text { value }\end{array}$ \\
\hline Overall satisfied with job (Agree, Strongly agree) & $78.7(71.9,84.2)$ & $74.0(69.3,78.2)$ & 0.264 & 1.0000 \\
\hline $\begin{array}{l}\text { Great deal of stress because of my job (Agree, Strongly } \\
\text { Agree) }\end{array}$ & $59.0(51.5,66.1)$ & $70.7(65.9,75.1)$ & 0.007 & 0.0505 \\
\hline $\begin{array}{l}\text { Symptoms of burnout (Definitely, Won't go away, } \\
\text { Completely) }\end{array}$ & $33.3(26.7,40.7)$ & $40.4(35.6,45.4)$ & 0.124 & 0.7468 \\
\hline Control over workload (Poor, Marginal) & $44.3(37.0,51.8)$ & $50.5(45.5,55.5)$ & 0.191 & 0.9544 \\
\hline Time for documentation (Poor, Marginal) & $47.5(40.2,55.0)$ & $69.2(64.3,73.7)$ & $<0.001^{\mathrm{a}}$ & 0.0000 \\
\hline Work atmosphere description (Very busy, Hectic-chaotic) & $57.9(50.4,65.1)$ & $58.1(53.0,63.0)$ & 1 & 1.0000 \\
\hline $\begin{array}{l}\text { Professional values well aligned with department leaders } \\
\text { (Agree, Strongly agree) }\end{array}$ & $68.3(61.0,74.9)$ & $63.9(58.9,68.6)$ & 0.345 & 1.0000 \\
\hline $\begin{array}{l}\text { Degree to which patient care team works efficiently } \\
\text { together (Satisfactory, Good, Optimal) }\end{array}$ & $86.9(80.9,91.3)$ & $67.9(63.0,72.5)$ & $<0.001^{\mathrm{a}}$ & 0.0000 \\
\hline $\begin{array}{l}\text { Amount of time spent on EMR at home (Moderate, High, } \\
\text { Excessive) }\end{array}$ & $45.9(38.6,53.4)$ & $62.1(57.1,66.9)$ & $<0.001^{\mathrm{a}}$ & 0.0028 \\
\hline Proficiency with EMR use (Satisfactory, Good, Optimal) & $90.7(85.3,94.3)$ & $88.4(84.7,91.3)$ & 0.489 & 1.0000 \\
\hline
\end{tabular}

CI confidence interval, EMR electronic medical record

${ }^{a}$ Statistically significant compared to cut-off using Holm-Bonferroni method for a family-wise error rate of 0.05 and ten comparisons for each

was less likely in respondents acknowledging high values alignment with leaders [OR $(95 \% \mathrm{CI}): 0.3,(0.2,0.5)$ $(p<0.001)]$.

Qualitative Findings. Table 4 shows the main worklife and wellness categories identified through content analysis of the open-ended survey question. Clinicians' comments highlighted an urgency to protect the specialty against market forces. Many comments demonstrated that clinicians felt committed to their patients but were losing the ability to provide high-quality care; as a result, some had reduced clinical practice, had moved to other clinical practice types, or felt that they would have to leave medicine. Hospitalists noted concerns about their patient censuses and sudden schedule changes; outpatient clinicians emphasized short visits and high volumes of nonface-to-face patient care and administrative work.
1. Workload: The category encompassed complex patients with multiple comorbidities, heavy clinical workloads leaving little time for other interest areas, and an "RVU [Relative Value Unit] mentality," a term used to encompass responses stating that respondents were pressured to improve RVU productivity, or had RVU targets that were felt to be unattainable. Representative comments included the challenges of seeing 12 complex patients in a session; no cap on the number of patients admitted per inpatient team; difficulties with short time slots to care for patients with limited English proficiency, mental health diagnoses, or addictions; stresses of meeting the demands of RVU targets; and not adjusting panel sizes for complex elderly patients. Clinicians felt overwhelmed and reported that seeing high numbers of patients was valued over care quality because the RVU system only compensated them for direct patient care, not associated visit care such as reading through lab results, coordinating care, and completing forms.

Table 4. Themes from Qualitative Analysis of Open-Ended Question "Tell Us More About Your Stressors and What We Can Do to Minimize Them" and Proposed Solutions

\begin{tabular}{|c|c|c|}
\hline Theme & Description & Proposed solutions \\
\hline 1. Workload & $\begin{array}{l}\text { Complex patient populations; RVU pressure; no } \\
\text { caps on inpatient censuses; }{ }^{a} \text { large panel sizes; } \\
\text { tension among academic, clinical, and teaching responsibilities }\end{array}$ & $\begin{array}{l}\text { Reduce reliance on RVUs; support interpreters; } \\
\text { right-size panels and inpatient censuses; } \\
\text { wellness as an organizational metric }\end{array}$ \\
\hline 2. Workday structure & $\begin{array}{l}\text { Short visit times; }{ }^{\mathrm{b}} \text { lack of schedule control; inadequate } \\
\text { physical space, }{ }^{\mathrm{b}} \text { sudden schedule changes }{ }^{\mathrm{a}}\end{array}$ & Longer visits; control of schedule \\
\hline 3. Staff support & $\begin{array}{l}\text { Understaffing or lack of appropriate types of support } \\
\text { staff for providers; poor communication with team } \\
\text { and other providers }\end{array}$ & Sufficient well-trained staff \\
\hline $\begin{array}{l}\text { 4. EMR stress/ } \\
\text { documentation burden }\end{array}$ & $\begin{array}{l}\text { High volume of administrative/clerical work; } \\
\text { lack of documentation time; EMR inefficiencies }\end{array}$ & $\begin{array}{l}\text { Account for indirect (non-face-to-face) work; } \\
\text { use scribes, templates, and standing orders; } \\
\text { IT support (training and } \\
\text { elbow-to-elbow mentoring) }\end{array}$ \\
\hline 5. Leadership & $\begin{array}{l}\text { Need for two-way communication and values alignment } \\
\text { with leadership; lack of transparency; lack of recognition } \\
\text { for work; desire for time to support education, research, } \\
\text { or professional development }\end{array}$ & $\begin{array}{l}\text { Support teaching; promote transparency, } \\
\text { values alignment, and leadership training }\end{array}$ \\
\hline 6. Work-home balance & $\begin{array}{l}\text { Excessive EMR documentation at home; limited time for } \\
\text { exercise, healthy eating, and spending time with family }\end{array}$ & $\begin{array}{l}\text { Support part-time; exercise; explicitly } \\
\text { support balance }\end{array}$ \\
\hline
\end{tabular}

EMR electronic medical record, RVU relative value units

${ }^{a}$ Hospitalists predominantly; ${ }^{b}$ non-hospitalists predominantly; all other items were mentioned by both hospitalists and non-hospitalists 
2. Workday structure: The category encompassed short visits, lack of schedule control, and insufficient and unsatisfying physical space. Comments highlighted unrealistic 20/40-min appointment times with clinicians routinely running behind until late in the evening, as well as chaotic clinics with a low sense of clinician control over clinic issues and schedules. Many providers found it impossible ("insanity") to see large numbers of complex patients in such short time slots.

3. Staff support: The category mainly encompassed insufficient numbers or training of support staff. Comments highlighted understaffing, lack of teamwork, and overwhelming clerical work for providers leading to long (14-h) days without breaks for food or rest.

4. EMR stress/documentation burden: The category encompassed work volume, lack of documentation time, EMR inefficiencies, and clerical rather than clinical skills use. Comments focused on excessive evening/weekend documentation time, concerns that the EMR focused on payers rather than patients, and observations that EMR requirements decreased volume of care and compensation. Clinicians stated that the joy of medicine was lost due to the EMR.

5. Leadership: The category encompassed needs for twoway communication and values alignment, lack of transparency and recognition for hard work, and requests for greater support for non-clinical interests, especially education. Comments highlighted the need for SGIM to advocate for recognition for teaching, requests that leadership seek input from front-line faculty, concerns about toxic or unhealthy work environments appearing unknown to leaders, and desires to avoid corporatizing health care. Many clinicians stated that leadership simply did not understand the distressing and challenging lives of front-line clinicians.

6. Work-home balance: The category encompassed excess charting at home and needs for exercise, healthy eating, and support for clinicians who are also parents. Comments highlighted that workdays bled into evening hours at home, with excess EMR work and challenges caring for children or elderly parents. Providers stated that while they needed to care for their families, workplaces seemed unaware of or unable to accommodate these challenges.

Potential Solutions. Constructive suggestions addressing workflow and workload issues included longer visit times for complex patients, increased staff support, APPs as part of evolving care teams, more efficient teams, inpatient volume caps, and decreased administrative focus on RVUs over patient care quality. Clinicians also recommended EMRrelated support, including protected EMR time during clinical sessions, scribes, more training in documentation strategies, and greater EMR focus on patient care issues than on billing.
Finally, leadership and work-home balance suggestions included more explicit support for work-life balance, exercise opportunities at work, more mentorship, clear support for teaching time, more time management training, mindfulness and resiliency, more protected time for administrative duties, grant-writing support, clearer compensation systems, and additional sessions with leadership to discuss values. Table 4 links solutions to categories of challenges raised within the qualitative analysis.

\section{DISCUSSION}

This national survey of 15 divisions and over 500 faculty in GIM found high stress and burnout, chaotic clinical environments, low sense of control, insufficient time for documentation, and excessive home EMR use. Open-ended comments emphasized the challenges of short visits for complex patients, lack of support staff for non-clinician functions, organizational ambivalence toward support for teaching, and needs for greater emphasis on work-life balance. These findings provide a substrate for solutions in terms of remediable factors that can be addressed through workflow redesign and communication improvements. ${ }^{10}$ Because many clinicians have already reduced involvement in primary care or plan to leave their practices, the need is urgent to reestablish a sustainable equilibrium between clinicians' work responsibilities and their devotion to patient care.

While faculty in the 15 divisions surveyed were diverse in terms of geography and role, findings were remarkably consistent. These results resonate with a recent article about the "quadruple aim," highlighting the need to address clinician worklife in order to improve morale, turnover, and patient care. ${ }^{11}$ Bodenheimer and Sinsky make clear recommendations, including pre-visit planning, team support, standardized workflows, and staff training, ${ }^{11}$ all of which would improve work conditions noted by respondents to the ACLGIM survey. We recently described the need to establish clinician wellbeing as an organizational metric, incorporate mindfulness and teamwork into the workplace, directly address EMRrelated stress, provide coverage for predictable life events with float clinicians, and support clinician self-care. ${ }^{12}$ These steps would also address many of the concerns noted above.

Notably, in 2003, we reported that general internists struggled with the dual roles of inpatient and outpatient care. ${ }^{13}$ The role of hospital medicine has since risen dramatically; however, according to our respondents, GIM worklife stress has not abated. While hospital-based clinicians exhibited better teamwork and fewer challenges than outpatient clinicians, particularly regarding less EMR-related time pressure at work, less EMR home use, and better teamwork, some were troubled by high inpatient censuses and sudden schedule changes. Meanwhile, outpatient clinicians described numerous concerns, 
emphasizing that reduced in-hospital care has not altered the challenging outlook for outpatient medicine.

What is needed to address current concerns and craft the future for the next generation of academic general internists? A position paper by ACLGIM and SGIM on worklife in academic GIM would be valuable to address concerns of learners considering the field. To address urgent concerns raised by clinicians we surveyed, we also suggest the following:

1. Reduce workload by incorporating adequate numbers of well-trained support staff, initiating workflow redesign activities including scribes, ${ }^{10,14}$ pre-visit planning, and allowing sufficient visit length for complex patients; ${ }^{15}$

2. Provide explicit support for educational functions; ${ }^{16}$

3. Measure and minimize EMR stress by accounting for indirect care time (non-face-to-face time spent using the EMR); ${ }^{11,17}$

4. Maximize use of EMR-based tools such as templates and standing orders;

5. Dedicate time and support to EMR user instruction to optimize how clinicians use the EMR;

6. Develop leadership training through ACLGIM and SGIM to improve responsiveness to clinician concerns, increase transparency, and improve advocacy for clinician worklife ${ }^{18}$

7. Explicitly address work-home balance, ${ }^{19}$ support parttime practice, ${ }^{20,21}$ and develop exercise options and wellness programs at work; ${ }^{22}$ and

8. Measure stress, burnout, and their predictors once or twice annually and use data to monitor success of local wellness programs.

There are limitations to our study. The project involved selfselected divisions of academic general internists, though there were wide-ranging burnout scores and substantial geographic diversity. Results reflected worklife among academic general internists and thus should apply mainly to academic GIM. Participating divisions paid $\$ 1500$ to join the study, which may have biased results toward more motivated divisions with greater willingness to change and lower burnout scores. The response rate was sub-optimal, though low response rates are typical of national physician studies. ${ }^{5,23,24}$ Finally, this study mainly focused on academic general internists rather than clinicians in practice; there were relatively few VA respondents and few APP respondents, so generalizability may be limited, especially regarding general internists in community-based practice. Larger studies ongoing through the American Medical Association and the American College of Physicians may shed more light on clinicians in office-based practice.

One outlier division demonstrated huge success in terms of worklife, wellness, and burnout predictors. We hope future work will illuminate best practices, especially interventions and emphases most likely to quickly improve GIM worklife and wellness. Until then, we suggest an immediate focus on clinician concerns surrounding office visits and clinical support, with concomitant measurement of worklife and wellness to assess improvements. The challenges are serious but not insurmountable. We look forward to a vigorous conversation around and response to the concerns of clinicians and educators in the ACLGIM Worklife and Wellness project.

Corresponding Author: Mark Linzer, MD; Division of General Internal MedicineHennepin County Medical Center, 701 Park Avenue (P7), Minneapolis, MN 55415, USA (e-mail: Mark.Linzer@hcmed.org).

\section{Compliance with Ethical Standards:}

Funding Support: This work received funding from Harvard Medical School's Center for Primary Care. Mr. Menk was supported by NIH Clinical and Translational Science Award 8UL1TROOO114-02 at the University of Minnesota.

Conflicts of Interest: The authors declare that they do not have a conflict of interest.

\section{REFERENCES}

1. Linzer M, Manwell LB, Williams ES, et al. Working conditions in primary care: Physician reactions and care quality. Ann Intern Med. 2009; 151(1):28-36. W6-W9.

2. Wetterneck TB, Linzer M, McMurray JE, et al. Worklife and satisfaction of general internists. Arch Intern Med. 2002;162(6):649-656.

3. Hauer KE, Durning SJ, Kernan WN, et al. Factors associated with medical students' career choices regarding internal medicine. JAMA. 2008;300(10):1154-1164. doi:10.1001/jama.300.10.1154.

4. Keeton K, Fenner DE, Johnson TRB, Hayward RA. Predictors of physician career satisfaction, work-life balance, and burnout. Obstet Gynecol. 2007;109(4):949-955. doi:10.1097/01.AOG.0000258299.45979.37.

5. Shanafelt TD, Boone S, Tan L, et al. Burnout and satisfaction with work-life balance among US physicians relative to the general US population. Arch Intern Med. 2012;172(18):1377-1385. doi:10.1001/archinternmed.2012.3199.

6. Shimotsu S, Poplau S, Linzer M. Validation of a brief clinician survey to reduce clinician burnout. In: Abstracts from the 38th Annual Meeting of the Society of General Internal Medicine. Vol 30, Issue 2 Supplement. Toronto, Canada: J Gen Intern Med. 2015:S79-S80. http://link.springer. com/journal/11606/30/2/suppl/page/1. Accessed March 31, 2016.

7. Rohland BM, Kruse GR, Rohrer JE. Validation of a single-item measure of burnout against the Maslach Burnout Inventory among physicians. Stress Health. 2004;20(2):75-79. doi:10.1002/smi. 1002.

8. Newcombe RG. Interval estimation for the difference between independent proportions: Comparison of eleven methods. Stat Med. 1998;17(8):873-890.

9. Holm S. A simple sequentially rejective multiple test procedure. Scand J Stat. 1979;6(2):65-70.

10. Linzer M, Poplau S, Grossman E, et al. A cluster randomized trial of interventions to improve work conditions and clinician burnout in primary care: Results from the Healthy Work Place (HWP) study. J Gen Intern Med. 2015;30(8):1105-1111. doi:10.1007/s11606-015-3235-4.

11. Bodenheimer T, Sinsky C. From Triple to Quadruple Aim: Care of the patient requires care of the provider. Ann Fam Med. 2014;12(6):573-576. doi: 10.1370/afm. 1713.

12. Linzer M, Levine R, Meltzer D, Poplau S, Warde C, West CP. 10 bold steps to prevent burnout in general internal medicine. J Gen Intern Med. 2014;29(1):18-20. doi:10.1007/s11606-013-2597-8.

13. Saint S, Zemencuk JK, Hayward RA, et al. What effect does increasing inpatient time have on outpatient-oriented internist satisfaction? J Gen Intern Med. 2003;18(9):725-729.

14. Bank AJ, Obetz C, Konrardy A, et al. Impact of scribes on patient interaction, productivity, and revenue in a cardiology clinic: A prospective study. Clin Outcomes Res CEOR. 2013;5:399-406. doi:10.2147/CEOR.S49010.

15. Linzer M, Bitton A, Tu S-P, et al. The end of the 15-20 minute primary care visit. J Gen Intern Med. 2015;30(11):1584-1586. doi:10.1007/ s11606-015-3341-3.

16. Shanafelt TD, West CP, Sloan JA, et al. Career fit and burnout among academic faculty. Arch Intern Med. 2009;169(10):990-995. doi:10.1001/ archinternmed.2009.70. 
17. Babbott S, Manwell LB, Brown R, et al. Electronic medical records and physician stress in primary care: Results from the MEMO Study. J Am Med Inform Assoc JAMIA. 2014;21(e1):e100-e106. doi:10.1136/amiajnl-2013001875.

18. Lee TH. Turning doctors into leaders. Harvard Business Review. https:// hbr.org/2010/04/turning-doctors-into-leaders. Accessed October 9, 2015

19. Warde C, Allen W, Gelberg DL. Physician role conflict and resulting career changes. J Gen Intern Med. 1996;11(12):729-735. doi:10.1007/ BF02598986.

20. Linzer $\mathbf{M}$, Warde $\mathbf{C}$, Alexander RW, et al. Part-time careers in academic internal medicine: A report from the Association of Specialty Professors Part-Time Careers Task Force on behalf of the Alliance for Academic Internal Medicine. Acad Med. 2009;84(10):1395-1400. doi:10.1097/ACM. ob013e3181b6bf8c.
21. Mechaber HF, Levine RB, Manwell LB, et al. Part-time physicians... Prevalent, connected, and satisfied. J Gen Intern Med. 2008;23(3):300303. doi:10.1007/s11606-008-0514-3.

22. Berry LL, Mirabito AM, Baun WB. What's the hard return on employee wellness programs? Harvard Business Review. https://hbr.org/ 2010/12/whats-the-hard-return-on-employee-wellness-programs. Accessed October 8, 2015.

23. Asch DA, Jedrziewski MK, Christakis NA. Response rates to mail surveys published in medical journals. J Clin Epidemiol. 1997;50(10): 1129-1136.

24. Kellerman SE, Herold J. Physician response to surveys. A review of the literature. Am J Prev Med. 2001;20(1):61-67. 